\title{
Metric sex determination from the pelvis in modern Greeks
}

M. Steyn*, M.Y. İşcan**

${ }^{*}$ Department of Anatomy, University of Pretoria,Pretoria, South Africa

${ }^{* *}$ Adli Tip Enstitüsü, Istanbul University, Cerrahpaşa, Turkey

\author{
Corresponding author: \\ M Steyn, Department of Anatomy, P.O. Box 2034, Pretoria 0001, South Africa \\ msteyn@medic.up.ac.za \\ Tel: 027-12-4203256 \\ Fax: 027-12-3192240
}




\begin{abstract}
The ability to determine sex from unknown skeletal remains is vital, and methods to do this on the various bones of the human skeleton have been researched extensively. Many researchers have emphasized the need for population specific data for methods which are based on measurements, as there are vast differences in body size in various populations. The pelvis is known to be the most sexually dimorphic part of the human body, and no discriminant function formulae for this bone are available for Greek or other Mediterranean groups. The purpose of this study was therefore to develop discriminant functions which can be used for sex determination on measurements of the pelvis of modern Greeks. A sample of 97 male and 95 female pelves in a skeletal collection housed in Heraklion, Crete, was used. Measurements were taken from the articulated pelvis, single os coxae and the sacrum. Discriminant function formulae for all measurements and various combinations were used in order to assess the degree of sexual dimorphism in various parts of the pelvis, and to make the formulae usable on fragmented remains. For the single os coxae, average accuracies of $79.7-95.4 \%(79.1-93.5 \%$ on crossvalidation) were found. However, it was found that measurements of the sciatic notch were unreliable and yielded poor results, and it is advisable that this characteristic must only be used as a last resort. Dimensions of the sacrum were not very dimorphic (average accuracy $60.9 \%$ ), while measurements from the articulated pelvis yielded poorer results than that from single innominate bones. The diameter of the acetabulum was the single most dimorphic characteristic, providing on average $83.9 \%$ accuracy when used in isolation.
\end{abstract}

Keywords: pelvis, sacrum, sexual dimorphism, osteometric analysis, discriminant function analysis, os coxa, innominate

\title{
1. Introduction
}

The correct determination of sex is a key aspect in the analysis of a skeleton from forensic and archaeological contexts. For this purpose, the pelvis has always been the most commonly used bone, providing the most accurate results. According to Krogman and İşcan [1], 95\% accuracy can be obtained if the pelvis is complete, although Bruzek [2] found that accuracies ranged from $59 \%$ to $96 \%$. However, it has widely been recognized that skeletal characteristics vary among populations (e.g., [3-7]), and due to this regional variability that each population should have specific standards to optimize the accuracy of identification. Several studies using a variety of measurements and characteristics of the pelvis have therefore been conducted from all over the world, with varying degrees of accuracy (e.g., [8-11]).

It has also been shown that some of the traditional characteristics in various parts of the skeleton, e.g., the shape of the greater sciatic notch [12], or gonial eversion [13] may not be as accurate as is commonly believed. New methods are constantly being developed (eg, [14]) and existing 
standards tested (e.g, [15-17]). These include both metric and morphological methods of assessing sexual dimorphism.

Seen in the light of the exceptional time depth and wealth of archaeological skeletal material from Greece and the Mediterranean area in general (e.g, [18-22]), it is surprising that relatively little research has been done on sex determination from the skeleton in this part of the world. Ari [7] studied the morphology of the greater sciatic notch in male Byzantine skeletons from Turkey, while Rissech et al. [23] studied skeletons from various collections from Europe, but concentrated more on age determination and growth. Duric et al. [24] studied remains from mass graves in Serbia, and found that they were very sexually dimorphic, such that they could be sexed with $100 \%$ accuracy using morphology alone. Of interest is the research by Albanese [25] who studied samples from both the Terry and a Portuguese collection, using both the hipbone and the femur, in an attempt to create standards which can be used across populations. He also investigated the repeatability of a new method to measure pubis and ischial length, and used a logistic regression analysis for sex determination.

The aim of this study was to collect metric data from the skeletons of modern Greeks, living on Crete, in order to develop discriminant function formulae that can be used to determine the sex of unknown adults. In this study the traditional measurements from articulated pelves, single os coxae and sacra were used. Various combinations of measurements were used, in order to assess the sexual dimorphism of various parts of the pelvis, and to make the formulae usable in fragmentary and incomplete remains.

\section{Materials and methods}

The materials for this study are housed in Heraklion, Crete, and were collected by members of the Department of Forensic Science, Medical School, University of Crete. The remains belong to modern Greek people who had lived on Crete and died during the past 50 years. Due to lack of space in graveyards, individuals are buried for a short period of time. After about 4 years, the remains are excavated if full decomposition has taken place and are then kept in boxes in mausoleums. The remains of these individuals may be destroyed if all their relatives are dead, or insufficient funds are available to keep them in the mausoleum (Kranioti, pers comm.).

The skeletal collection is comprised of approximately 100 male and 100 female individuals, but due to the presence of soft tissue and damage to some of the bones, a total of 97 male and 95 female pelves could be measured. A full set of measurements could not be obtained from each of these individuals, mostly due to the presence of dried soft tissue, but sample size for each of the measurements ranged between 72 and 94 (Table 1). Using standard anthropometric techniques $[1,11,26,27]$, the following 17 measurements were taken:

1. Pubic length: measured using a sliding caliper from the most medio-superior point of the pubis to the closest point on the acetabular rim. 
2. Height of the pubic symphysis : measured from the most superior to the most inferior point on the pubic symphysis [8].

3. Ischial length: measured using a sliding caliper from the most distal point of the ischium to the closest point on the rim of the acetabulum.

4. Pubic tubercle-acetabulum length: measured with a sliding caliper from the highest point of the pubic tubercle to the nearest point on the acetabulum.

5. Total innominate height: the greatest distance from the most superior point on the iliac crest to the most inferior point of the ischial tuberosity [26].

6. Iliac width: the greatest distance from the anterior superior to the posterior superior iliac spines [26].

7. Greater sciatic notch breadth: measured from the base of the ischial spine to the posterior inferior iliac spine stopping at a point before the curvature of the spine angles to the posterior [11]. This was measured on a graph paper, so that the two points from which the measurements were taken were on the same horizontal line on the graph paper.

8. Greater sciatic notch depth: measured with the bone in the same position as for (9), but at the deepest edge of the notch perpendicular to the line between the two points mentioned in (9). This is in essence the same measurement as that of Patriquin et al, but just measured on graph paper rather than with a caliper in order to attempt to improve accuracy.

9. Acetabular diameter: maximum diameter of the acetabulum measured in a superiorinferior direction [28].

10. Anterior length of sacrum: measured with spreading caliper from the middle point of promontorium to the middle point of the inferior border of the sacrum.

11. Anterior straight breadth of sacrum: measured with sliding caliper as the distance between the left and right auricular surfaces.

12. Maximum breadth $\mathrm{S} 1$ : maximum breadth of $\mathrm{S} 1$ on the superior surface of the sacrum, measured with a sliding caliper.

13. Bi-iliac diameter (articulated pelvis): maximum distance between the iliac crests measured with an osteometric board after the articulation of the pelvis [1].

14. Conjugate vera: antero-posterior diameter of the pelvic inlet measured with a sliding caliper in an articulated pelvis.

15. Transverse diameter: maximum distance between the arcuate lines measured in an articulated pelvis with a sliding caliper. 
In order to test for intra-observer repeatability of the measurements, the pelves of 30 randomly selected individuals, including both males and females, were remeasured by MS after the completion of the collection of the original dataset. The two sets of values for these 30 individuals were compared by means of a paired Students' t-test.

\begin{tabular}{|c|c|c|c|c|c|c|c|c|c|}
\hline & & & Male & & & & nale & & \\
\hline & $\mathrm{N}$ & Mean & Std. Deviation & SE Mean & $\mathrm{N}$ & Mean & $\begin{array}{r}\text { Std. } \\
\text { Deviation } \\
\end{array}$ & $\begin{array}{r}\text { SE } \\
\text { Mean } \\
\end{array}$ & Sig \\
\hline Publng & 94 & 70.35 & 4.48 & 0.46 & 81 & 73.21 & 4.37 & 0.49 & 0.000 \\
\hline Pubsymph & 93 & 40.86 & 3.38 & 0.35 & 77 & 37.10 & 4.14 & 0.47 & 0.000 \\
\hline Ischlng & 95 & 56.74 & 3.29 & 0.34 & 92 & 51.55 & 4.57 & 0.48 & 0.000 \\
\hline Tubac & 90 & 53.90 & 5.42 & 0.57 & 79 & 52.65 & 5.67 & 0.70 & $0.144^{*}$ \\
\hline Totalht & 95 & 214.62 & 9.20 & 0.94 & 90 & 199.86 & 8.90 & 0.94 & 0.000 \\
\hline Iliacwth & 94 & 159.26 & 7.52 & 0.78 & 91 & 154.51 & 7.27 & 0.76 & 0.000 \\
\hline Notchbr & 93 & 43.37 & 3.94 & 0.41 & 84 & 50.96 & 5.89 & 0.64 & 0.000 \\
\hline Notchdpt & 93 & 28.68 & 4.68 & 0.49 & 84 & 30.58 & 4.40 & 0.48 & 0.006 \\
\hline Acet & 92 & 54.59 & 3.07 & 0.32 & 94 & 49.15 & 2.76 & 0.28 & 0.000 \\
\hline Sacrlngth & 78 & 108.81 & 12.08 & 1.37 & 81 & 101.70 & 11.19 & 1.24 & 0.000 \\
\hline Sacrbr & 83 & 116.57 & 6.06 & 0.67 & 91 & 115.61 & 6.33 & 0.66 & $0.308^{*}$ \\
\hline S1br & 72 & 49.46 & 4.16 & 0.49 & 78 & 47.09 & 4.68 & 0.53 & 0.001 \\
\hline Bi-iliac & 84 & 276.86 & 14.43 & 1.57 & 86 & 275.16 & 21.25 & 2.29 & $0.542 *$ \\
\hline Conjvera & 85 & 103.21 & 8.54 & 0.93 & 83 & 113.33 & 9.27 & 1.02 & 0.000 \\
\hline Trdiam & 85 & 124.66 & 7.79 & 0.84 & 86 & 130.69 & 7.51 & 0.81 & 0.000 \\
\hline
\end{tabular}

* not

significant

Table 1

Descriptive statistics for the pelvic measurements. (Publng = pubic length, Pubsymph $=$ height of the pubic symphysis, Ischlng = ischial length, Tubac = pubic tubercle-acetabulum length, Totalht = total innominat height, lliacwth = iliac width; Notchbr = greater sciatic notch breadth, Notchdpt = greater sciatic notch depth, Acet = acetabular diameter, Sacrlngth = anterior length of sacrum, Sacrbr = anterior straight breadth of sacrum, S1br = maximum breadth S1, Bi-iliac $=$ bi-iliac diameter, Conjvera = conjugate vera, Trdiam $=$ transverse diameter

Standard descriptive statistics, including means and standard deviations, were obtained for all measurements. Significance of differences between the sexes was assessed by means of a oneway ANOVA analysis. Data were then subjected to statistical analysis using the SPSS program.

Firstly, all dimensions on a single innominate bone (pubic length, height of the pubic symphysis, ischial length, pubic tubercle-acetabulum length, total innominate height, iliac width, greater sciatic notch width and depth and acetabular diameter) were entered into a stepwise discriminant function procedure using Wilks' lambda, to determine which variable provided the best 
discrimination between the sexes (Function 1). $F$ to enter was 3.84 and $F=2.71$ to remove. Stepwise analysis incorporated all pelvic dimensions that were systematically added and removed from the list. Once the first variable is selected it is removed from the analysis and the remaining variables are reassessed and selected.

\begin{tabular}{llll}
\hline Step & Variables entered & Wilks' lamda & $\begin{array}{l}\text { Degrees } \\
\text { of freedom }\end{array}$ \\
\hline 1 & Acetabular diameter & 0.569 & 150 \\
2 & Sciatic notch breadth & 0.430 & 149 \\
3 & Total height & 0.360 & 148 \\
4 & Pubic length & 0.292 & 147 \\
5 & Ischial length & 0.275 & 146 \\
6 & Pubic tubercle-acetabular length & 0.263 & 145 \\
& & \\
\hline
\end{tabular}

Table 2

Stepwise discriminant function analysis of pelvic dimensions, Function 1.

The same analysis was also performed on the measurements for various parts of the pelvis, but this time using a direct approach. These were grouped as all the measurements of the pubis and ischium (Function 2), the measurements of the complete innominate bone only (total innominate height and iliac width, Function 3), the sciatic notch width and depth (Function 4), the measurements of the sacrum (Function 5) and the three measurements for the articulated pelvis (Function 6). An additional function (Function 7), was also calculated using only the variable that was chosen first (thus the best discriminator) by the stepwise analysis.

To measure the effectiveness of the functions, a "leave one out" classification procedure was performed. This classifies each individual bone by the functions derived from all cases other than that case itself. This process continues for all individual bones, until all are tested. Through this process the accuracy of assignments to either male or female categories is thus crossvalidated.

Of the 192 individuals used in this study, the ages of only 122 were noted in the records. The sample comprised mostly of older individuals with a mean age of just above 70 years, and with so few younger individuals the effect of age on sex determination could not be assessed. 


\begin{tabular}{|c|c|c|c|c|}
\hline Functions and variables (mm) & $\begin{array}{l}\text { Standard } \\
\text { coefficients }\end{array}$ & $\begin{array}{l}\text { Structure } \\
\text { coefficients }\end{array}$ & Unstand coefficients & Centroids \\
\hline \multicolumn{5}{|l|}{ Function 1 (complete bone) } \\
\hline Acetabular diameter & 0.436 & 0.519 & 0.146 & $\mathrm{M}=1.477$ \\
\hline Sciatic notch breadth & -0.431 & -0.443 & -0.084 & $F=-1.874$ \\
\hline Total height & 0.474 & 0.491 & 0.052 & \\
\hline Pubic length & -0.752 & -0.183 & -0.171 & \\
\hline Ischial length & 0.363 & 0.510 & 0.116 & \\
\hline Pubic tub-acetab length & 0.276 & -0.099 & 0.052 & \\
\hline Constant & & & -11.388 & \\
\hline Sectioning point & & & -0.199 & \\
\hline \multicolumn{5}{|l|}{ Function 2(pubis \& ischium) } \\
\hline Pubic length & -0.987 & -0.272 & -0.221 & $M=1.006$ \\
\hline Height pubic symphysis & 0.612 & 0.442 & 0.166 & $F=-1.288$ \\
\hline Ischial length & 0.749 & 0.526 & 0.185 & \\
\hline Pubic tub-acetab length & 0.466 & 0.142 & 0.088 & \\
\hline Constant & & & -5.505 & \\
\hline Sectioning point & & & -0.141 & \\
\hline \multicolumn{5}{|l|}{ Function 3(complete bone) } \\
\hline Total height & 1.179 & 0.961 & 0.131 & $\mathrm{M}=0.818$ \\
\hline Iliac width & -0.353 & 0.377 & -0.048 & $F=-0.864$ \\
\hline Constant & & & -19.560 & \\
\hline Sectioning point & & & -0.023 & \\
\hline \multicolumn{5}{|l|}{ Function 4(sciatic notch) } \\
\hline Sciatic notch width & 0.994 & 1.000 & 0.200 & $M=-0.726$ \\
\hline Sciatic notch depth & 0.023 & .273 & 0.005 & $\mathrm{~F}=0.804$ \\
\hline Constant & & & -9.552 & \\
\hline Sectioning point & & & 0.039 & \\
\hline \multicolumn{5}{|l|}{ Function 5 (sacrum) } \\
\hline Sacrum length & 0.669 & 0.739 & 0.059 & $M=0.418$ \\
\hline Sacrum breadth & -0.283 & 0.186 & -0.045 & $F=-0.376$ \\
\hline S1 breadth & 0.730 & 0.764 & 0.163 & \\
\hline Constant & & & -8.868 & \\
\hline Sectioning point & & & 0.021 & \\
\hline \multicolumn{5}{|l|}{ Function 6 (articulated) } \\
\hline Bi-iliac diameter & -0.659 & -0.019 & -0.039 & $\mathrm{M}=-0.783$ \\
\hline Conjugate vera & 0.818 & 0.731 & 0.092 & $\mathrm{~F}=0.793$ \\
\hline Transverse diameter & 0.768 & 0.508 & 0.100 & \\
\hline Constant & & & -11.979 & \\
\hline Sectioning point & & & 0.005 & \\
\hline \multicolumn{5}{|l|}{ Function 7 (acetabulum) } \\
\hline Acetabular diameter & 1.000 & 1.000 & 0.343 & $\mathrm{M}=0.944$ \\
\hline Constant & & & -17.782 & $F=-0.924$ \\
\hline Sectioning point & & & 0.01 & \\
\hline Demarking point & & & Female $<51.87>$ Male & \\
\hline
\end{tabular}

\section{Table 3}

Canonical discriminant function coefficients for pelvic dimensions. Function 1 was derived by means of a stepwise analysis, all others by a direct analysis. 


\section{Results}

All measurements yielded non-significant values between the two groups of 30 randomly selected specimens when tested for intra-observer repeatability, with the exception of sciatic notch depth $(p<0.01)$. This showed that all measurements were repeatable and could be measured with a high degree of accuracy, excluding the measurement of sciatic notch depth.

The descriptive statistics are shown in Table 1. Most of the measurements show statistically significant differences between the two sexes, excluding three measurements namely pubic tubercle-acetabular length, width of the sacrum, and the bi-iliac width in the articulated pelves. As expected, the pubis is longer in females, although the symphyseal height is more in males. The ischium is larger in males, as is the acetabulum, the total height of the innominate, the iliac width and sacral length. The sciatic notch is wider and deeper in females, who also have longer pubic bones and larger pelvic inlets.

Table 2 displays the results of the stepwise analysis of pelvic dimensions. For function one, all dimensions on the unarticulated os coxa were entered and acetabular diameter was selected first, followed by sciatic notch breadth. Only six of the nine variables entered were selected, with sciatic notch depth, pubic symphysis height and iliac width not included. The degrees of freedom is less than the total number of individuals as displayed in Table 1, as all individuals without a complete set of variables for the included measurements were left out.

The standard, structure and unstandardized coefficients as well as the centroids and sectioning points are shown in Table 3 for all functions, including those that were derived from direct analyses (Functions 2-7). In order to use these formulae the value of the variable (measured in $\mathrm{mm}$ ) should be multiplied by the unstandarized coefficient, and added/subtracted to each other. This value should then be added/subtracted to the constant. If the obtained value is less than the sectioning point in Functions 1, 2, 3, 5 and 7, the individual is a female, and larger a male. The opposite is true for Functions 4 and 6, where a value larger than the sectioning point indicates a female and vice versa. As the sample sizes for males and females are not equal, the sectioning points are not zero. For example, for Function 3 if Total Height is $216 \mathrm{~mm}$ and lliac Width is 160 $\mathrm{mm}$, the equation should be: $(0.131 \times 216)-(0.048 \times 160)-19.560=1.056$. This is larger than the sectioning point of -0.023 , indicating a male.

For Function 7 a demarcation point was included, which simply means that a value for the acetabular diameter of less than $51.87 \mathrm{~mm}$ would indicate a female, and more than that a male. Obviously if a value is close to this demarcation point, the possibility of error is larger, but if it is further it will be more accurate.

The accuracies for these functions, including the leave-one-out analysis, are shown in Table 4. Function 1, where all the variables on a single os coxa were included, showed the best results, being on average $95.4 \%$ accurate. Three females were lost during cross-validation, bringing the 


\begin{tabular}{rlcccc}
\hline \multicolumn{1}{l}{ Functions } & Males & \multicolumn{3}{c}{ Females } & $\begin{array}{c}\text { Average } \\
\text { accuracy }\end{array}$ \\
\cline { 2 - 6 } & Count & $\%$ & Count & $\%$ & \\
\hline Function 1 & & & & & \\
Original & $82 / 85$ & 96.5 & $64 / 68$ & 94.1 & 95.4 \\
Cross-validated & $82 / 85$ & 96.5 & $61 / 68$ & 89.7 & 93.5
\end{tabular}

Function 2

$\begin{array}{rrrrrr}\text { Original } & 78 / 87 & 89.7 & 60 / 68 & 88.2 & 89.0 \\ \text { Cross-validated } & 78 / 87 & 89.7 & 60 / 68 & 88.2 & 89.0\end{array}$

Function 3

$\begin{array}{rrrrrr}\text { Original } & 80 / 94 & 85.1 & 72 / 89 & 80.9 & 83.1 \\ \text { Cross-validated } & 80 / 94 & 85.1 & 72 / 89 & 80.9 & 83.1\end{array}$

Function 4

$\begin{array}{rrrrrr}\text { Original } & 81 / 93 & 87.1 & 60 / 84 & 71.4 & 79.7 \\ \text { Cross-validated } & 81 / 93 & 87.1 & 59 / 84 & 70.2 & 79.1\end{array}$

Function 5

$\begin{array}{rrrrrr}\text { Original } & 34 / 63 & 54.0 & 47 / 70 & 67.1 & 60.9 \\ \text { Cross-validated } & 34 / 63 & 54.0 & 45 / 70 & 64.3 & 59.4\end{array}$

Function 6

$\begin{array}{rrrrrr}\text { Original } & 66 / 84 & 78.6 & 64 / 83 & 77.1 & 77.8 \\ \text { Cross-validated } & 65 / 84 & 77.4 & 64 / 83 & 77.1 & 77.2\end{array}$

Function 7

$\begin{array}{rlllll}\text { Original } & 80 / 92 & 87.0 & 76 / 94 & 80.9 & 83.9 \\ \text { Cross-validated } & 80 / 92 & 87.0 & 76 / 94 & 80.9 & 83.9\end{array}$

Table 4

Percentage accuracy and cross-validation for the derived formulae

accuracy down to $93.5 \%$. The pubis and ischium measurements were also very accurate, with $89 \%$ of individuals correctly classified. This dropped to around $80 \%$ when only the sciatic notch measurements (Function 4) or measurements of the whole bone (Function 3) were used. It seems that it is hardly worthwhile to measure an articulated pelvis, because the results of measuring individual os coxae are much better (Function 6, 77.8\% accuracy). The sacrum in this population is not very dimorphic at all, with accuracies that are hardly more than chance $(54 \%$ for males and $67 \%$ for females). Measuring the acetabulum only provided fairly good results, with about $84 \%$ of individuals correctly classified. 


\section{Discussion}

Forensic anthropologists are continually attempting to improve methods of skeletal identification through development of new methods of determining sex or fine-tuning of existing methods on various parts of the skeleton so that it can be admissible in court [e.g., 29,30]. The aim of this paper was to follow in this tradition, by developing population specific formulae that could be used on people living in Greece and the Mediterranean.

Some measurements in the pelvis may be very difficult to record accurately [31]. In this study it was found that all measurements were highly repeatable, with the exception of the sciatic notch depth. This fact, coupled with the low levels of accuracy obtained for sciatic notch measurements when used in isolation (Function $4 ; 79.1 \%$ ), makes measurements and formulae based on sciatic notch dimensions less reliable. Some studies have shown that size of the greater sciatic notch may not be a very good characteristic to use in sex determination and that it may vary between populations (e.g., [11,12,32]. Rösing et al. [33] stated that outside of Europe this feature often does not permit reliable sex determination, but this may well be true of European populations as well (see also [24]). It thus seems that this characteristic is unreliable both when applied in a metric or morphological assessment, and that other features of the pelvis can provide more reliable results. Walker [32] found that sciatic notch shape is also influenced by age, and this may be something to take into account too.

It is interesting to note that three of the measurements (bi-iliac breadth, sacrum breadth and pubic-tubercle acetabular length) are not dimorphic at all. As far as the bi-iliac breadth is concerned, this is probably due to the fact that the relatively wider hips expected in females is being "obscured" by the larger body size of males, leading to very similar overall dimensions. It therefore seems that measuring the complete pelvis would not provide better results than measuring the disarticulated bones, as also comfirmed from the low accuracies of Function 6 . It is also interesting to note that the dimension which is the most dimorphic (acetabular diameter) is one that is associated simply with robusticity, and has nothing to do with child bearing at all. This measurement was also found to be one of the best indicators of sexual dimorphism in similar studies $[5,11,34]$.

Studies in the metric characteristics of male and female sacra seem to be less numerous than that for the rest of the pelvis. The reports concerning results and accuracies also seem to be quite different, with some authors finding it usable and others less so (e.g., [35-38]). In this study the accuracy of the discriminant function for the sacrum is particularly disappointing, with only about $60 \%$ of the study sample classified correctly. Females are classified with more accuracy than males. The male sacrum seems to be more variable, making it nearly impossible to use metric methods for sex determination.

The accuracies with which sex can be determined using discriminant function formulae in this population is on a par with that found in several other studies. The $95 \%$ accuracy when using all 
measurements (dropping to $93 \%$ after cross-validation) is similar to that found, for example, by Schulter-Ellis et al. [27] on an American sample (95-98\%) and Patriquin et al. [11] on a South African sample (up to $91 \%$ ). It seems that most of the differences in the pelves between the sexes are situated in the pubic and ischial parts. Absolute size (robusticity), however, also plays a significant role as can be seen by the fact that acetabular diameter was selected first in the stepwise analysis and total bone size also gave good results.

The accuracies found here are also similar to that of Albanese [28] who used logistic regression to determine sex (allocation accuracy of $90-95 \%$ ). As this author suggested, a future avenue of research should now be to combine various datasets of populations across the continent, to see whether it is possible to employ more global standards. It would also be of interest to see whether results of logistic regression and discriminant functions are on a par as far as their accuracies are concerned.

In summary, this paper provides discriminant function formulae that can be used with high levels of accuracy on Greek populations. Single innominate bones provided better results than the sacrum or articulated pelvis. The sciatic notch depth measurement is difficult to repeat, and also does not seem to contribute much to the ability to distinguish between the sexes. This population is very dimorphic as far as pelvic dimensions are concerned, and the results are on a par with those on other populations. Factors such as secular trends, the influence of body size on pelvic dimensions [39], age at death [32] and nutrition were not taken into account, and may play a role which needs to be taken into account when using these formulae on other populations, specifically those from archaeological contexts.

\section{Acknowledgements}

M Steyn would like to thank Prof M Michalodimitrakis and Dr E Kranioti for their hospitality during the stay on Crete. Funding was provided by the University of Pretoria.

\section{References}

1. W.M. Krogman, M.Y. İşcan, The Human Skeleton in Forensic Medicine, Charles C. Thomas, Springfield, IL, 1986.

2. J. Bruzek, A method for visual determination of sex, using the human hip bone, Am. J. Phys. Anthropol. 117 (2002)157-168.

3. G.S. Letterman, The greater sciatic notch in American Whites and Negroes, Am. J. Phys. Anthropol. 28 (1941) 99-116.

4. R. DiBennardo, J.V. Taylor, Multiple discriminant function analysis of sex and race in the postcranial skeleton, Am. J. Phys. Anthropol. 61 (1983) 305-314. 
5. S.M. MacLaughlin, M.F. Bruce, Sex determination from the pelvis in a Dutch skeletal series, J. Anat. 140 (1985) 532.

6. C.A. King, S.R. Loth, M.Y İşcan, Metric and comparative analysis of sexual dimorphism in the Thai femur, J. Forensic Sci. 43 (1998) 954-958.

7. I. Ari, Morphometry of the greater sciatic notch on remains of male Byzantine skeletons from Nicea, Eur. J. Anat, 9 (2005) 161-165.

8. V. Davivongs, The pelvic gridle of the Australian Aborigine; sex differences and sex determination, Am. J. Phys. Anthropol. 21 (1963) 443-445.

9. S. Jovanovic, S. Zivanovic, The establishment of sex by the greater sciatic notch, Acta Anatomica 61 (1965) 101-107.

10. T.B. Akpan, A.O. Igiri, S.P. Singh, Greater sciatic notch in sex determination in Nigerian skeletal samples, Afr. J. Med. Sci. 27 (1998) 43-46.

11. M.L. Patriquin, M. Steyn, S.R. Loth, Metric analysis of sex differences in South African black and white pelves, Forensic Sci. Int 147 (2005) 119-127.

12. M. Steyn, E. Pretorius, L. Hutten, Geometric morphometric analysis of the greater sciatic notch in South Africans, Homo 54 (3) (2004) 197-206.

13. S.R. Loth, M. Henneberg, M., Gonial eversion: facial architecture, not sex, Homo 51 (2000) 81-89.

14. S.R. Loth, M. Henneberg, Mandibular ramus flexure: a new morphologic indicator of sexual dimorphism in the human skeleton, Am. J. Phys. Anthropol. 99 (1996) 473-485.

15. K. Koski, Mandibular ramus flexure - indicator of sexual dimorphism? Am. J. Phys. Anthropol. 101 (1996) 545-546.

16. A, Kemkes-Grottenthaler, F. Lobig, F. Stock, Mandibular ramus flexure and gonial eversion as morphological indicators of sex, Homo 53/2 (2002) 97-111.

17. E. Pretorius, M. Steyn, Y Scholtz, Investigation into the usability of geometric morphometric analysis in assessment of sexual dimorphism, Am. J. Phys. Anthropol. 129 (2006) 1:64-70.

18. J.L.Angel, Porotic hyperostosis, anemias, malarias and marshes in the prehistoric Eastern Mediterranean, Science 153 (3737) (1966) 760-763.

19. J.L. Angel, The people of Lerna, American School of Classical Studies at Athens Princeton New Jersey and Smithsonian Institution Press, 1971. 
20. J.L. Angel, Health as a crucial factor in the changes from hunting to developed farming in the Eastern Mediterranean, in: M.N. Cohen, G.J. Armelagos (Eds), Paleopathology at the Origins of Agriculture, Academic Press, New York, 1984, pp. 51-73.

21. M. Henneberg, R.J. Henneberg, Biological characteristics of the population based on analysis of skeletal remains, in: J.C. Carter (Ed), The Chora of Metaponto: The Necropolis, Vol II, University of Texas Press, Austin; 1998, pp. 503-562.

22. A. Keenleyside, H Schwarcz, K Panayotova, Stable isotopic evidence of diet in a Greek colonial population from the Black Sea, Journal Arch. Sci. 33 (2006) 1205-1215.

23. C. Rissech, M. Garcia, A. Malgosa, Sex and age diagnosis by ischium morphometric analysis, Forensic Sci. Int. 135 (2003), 188-196 .

24. M. Đurić, Z. Rakočević, D. Đonića, The reliability of sex determination of skeletons from forensic context in the Balkans, Forensic Sci. Int. 147 (2005) 159-164.

25. J. Albanese, A metric method for sex determination using the hip bone and the femur, J. Forensic Sci. 48 (2) (2003) 263-273.

26. R. Martin, K. Saller, Lehrbuch der Anthropologie, Gustav Fischer, Stuttgart, 1957.

27. F.P. Schulter-Ellis, L.C Hayek, D.J. Schmidt, Determination of sex with a discriminant analysis of new pelvic bone measurements: Part II, J. Forensic Sci. 30 (1) (1985) 178185.

28. M.A. Kelley, Sex determination with fragmented skeletal remains, J. Forensic Sci. 24 (1979) 154-158.

29. T.L. Rogers, Determining the sex of human remains through cranial morphology, J. Forensic Sci. 50 (3) (2005) 493-500.

30. B.A. Williams, T.L. Rogers, Evaluating the accuracy and precision of cranial morphological traits for sex determination, J. Forensic Sci. 51 (4) (2006) 729-735.

31. J. Bruzek, P. Murail, F. Houët, E. Cleuvenot, Inter- and intra-observer error in pelvic measurements and its implication for the methods of sex determination, Anthropologie 32 (3) (1994) 215-223

32. P.L. Walker, Greater sciatic notch morphology: Sex, age, and population differences, Am. J. Phys. Anthropol. 127 (4) (2005) 385-391.

33. F .W. Rösing, M. Graw, B. Marréc, S. Ritz-Timmed, M.A. Rothschilde, K. Rötzscherf, A. Schmelingg, I. Schröderh, G. Geserickg, Recommendations for the forensic diagnosis of sex and age from skeletons, Homo 58 (1) (2007) 75-89. 
34. T. Rogers, S. Saunders, Accuracy of sex determination using morphological traits of the human pelvis, J. Forensic Sci. 39 (1994) 1047-1056.

35. S.R. Mishra, P.J. Singh, A.K. Agrawal, R.N. Gupta, Identification of sex of sacrum of Agra region, J. Anat. Soc. Ind. 52 (2) (2003) 7-12.

36. L.B. Flander, Univariate and multivariate methods for sexing the sacrum, Am. J. Phys. Anthrop. 49 (1978) 103-110.

37. V. Stradalova, 1975, Sex differences and sex determination from the sacrum, Anthropologie 13 (1975) 237-244

38. K. Kimura, A base-wing index for sexing the sacrum, J Anthrop Soc. Nippon, 90 suppl (1982) 153-162.

39. J.L. Arsuaga, J.M. Carretero, Multivariate analysis of the sexual dimorphism of the hip bone in a modern human population and in early hominids, Am. J. Phys. Anthrop. 93 (2) (1994) 241-257. 